\title{
DETERMINATION OF ETHYL 2-CHLOROACETATE AS A GENOTOXIC IMPURITY IN NITROFURANTOIN BY GAS CHROMATOGRAPHY
}

\author{
P. Murali Krishna, L. Vikuntarao, K. Ramakrishna* and V. Srinivasarao \\ Gitam Institute of Science, Department of Chemistry, GITAM University, \\ Visakhapatnam-530045, Andhra Pradesh, India. \\ *E-mail: karipeddirk@gmail.com
}

\begin{abstract}
The purpose is to develop a method for identification and quantification of Ethyl 2-chloroacetate in Nitrofurantoin at trace level by using the simple gas chromatographic technique. The method was validated as per ICH guideline in terms of LOD, LOQ, Method precision, accuracy and specificity. The LOD and LOQ values were found as 0.38ppm and $1.1 \mathrm{ppm}$ respectively.

Keywords: Development, validation, Ethyl 2-chloroacetate, Nitrofurantoin, Gas chromatography.
\end{abstract}

(C) RASĀYAN. All rights reserved

\section{INTRODUCTION}

Ethyl 2-chloroacetate is used as raw material in the manufacturing of Nitrofurantoin. Ethyl 2chloroacetate is a clear colorless liquid with a fruity, pungent odor with a density of $1.145 \mathrm{~g} / \mathrm{mL}$ and a boiling point of $143^{\circ} \mathrm{C}$.It is a flammable compound having an empirical formula of $\mathrm{C}_{4} \mathrm{H}_{7} \mathrm{ClO}_{2}$ and molecular weight of $122.55 \mathrm{~g} / \mathrm{mol}$

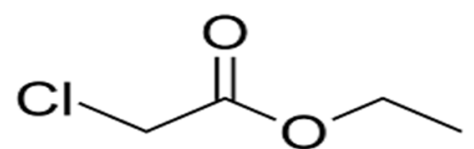

Fig-1: Ethyl 2-Chloroacetate

There are few methods available for the determination of Nitrofurantoin and its relative impurities in the literature by using HPLC, Stripping, Voltammetry and UV Spectrophotometry. The literature search clearly suggests that no analytical method is available for identification of Ethyl 2-chloroacetate in Nitrofurantoin as a genotoxic impurity. So important to develop a method for identification of Ethyl 2chloroacetate in nitrofurantoin. Hence analytical method was developed for Ethyl 2-chloroacetate in Nitrofurantoin, which is a stability indicating method.

\section{Reagents and Chemicals}

\section{EXPERIMENTAL}

Ethyl 2-chloroacetate: Sigma Aldrich, LC grade n-hexane: Rankem.

Samples of Nitrofurantoin: Local market

\section{Chromatography Conditions}

Column $\quad$ : Length $30 \mathrm{~m}$ and internal diameter $0.32 \mathrm{~mm}$ I.D x $1.0 \mu \mathrm{m}$ DB-1

Detector : FID

Inj temp $\quad: 250^{\circ} \mathrm{C}$

Det temp $\quad: 270^{\circ} \mathrm{C}$

Rasayan J. Chem., 12(1), 355-359(2019)

http://dx.doi.org/10.31788/RJC.2019.1211624 
RASĀYAN J. Chem.

Vol. 12 | No. 1 |355 - 359| January - March | 2019

Column temp programme: Initial $60{ }^{\circ} \mathrm{C}$ with the hold of 5 minutes, raise rate of $40{ }^{\circ} \mathrm{C} / \mathrm{min}$ to final temperature $260^{\circ} \mathrm{C}$ and hold for 20 minutes

$\begin{array}{ll}\text { Carrier gas } & : \text { Helium } \\ \text { Flow } & : 1.0 \mathrm{~mL} / \mathrm{min} \text { (Constant velocity) } \\ \text { Mode } & : \text { Split } \\ \text { Split ratio } & : 1: 2 \\ \text { Injection volume } & : 2.0 \mu \mathrm{L} \\ \text { Diluent } & : \text { n-hexane }\left(\mathrm{C}_{6} \mathrm{H}_{12}\right)\end{array}$

Instrumentation

GC Agilent 6890B with autosampler

FID detector

Carrier Gas: Helium

\section{Preparation of Standard Solutions}

Ethyl 2-chloroacetate solution was prepared by weighing $37.5 \mathrm{mg}$ of Ethyl 2-chloroacetate in a $100 \mathrm{~mL}$ volumetric flask and make up to $100 \mathrm{~mL}$ with diluent. Taken $2 \mathrm{~mL}$ from the above flask and diluted to $50 \mathrm{~mL}$ using diluent.

$5 \mathrm{~mL}$ above mentioned solution and diluted to $100 \mathrm{~mL}$. (Equivalent to $3.75 \mathrm{ppm}$ with respect to sample concentration $200 \mathrm{mg} / \mathrm{ml}$ as per maximum daily dosage $400 \mathrm{mg}$, i.e. TTC $=1.5 /$ daily dosage grams).

\section{Test Solution}

Weighed about $400 \mathrm{mg}$ of Nitrofurantoin drug substance into $5 \mathrm{~mL}$ volumetric flask, added $2 \mathrm{~mL}$ of diluent (n-hexane) shake well and filtered through a $0.45 \mu$ filter. The filtered solution used for sample injection.

\section{Method Development and Optimization}

\section{RESULTS AND DISCUSSION}

The purpose is to develop a method for identification and quantification of Ethyl 2-chloroacetate in Nitrofurantoin at trace level by using the simple gas chromatographic technique. Ethanol, acetone, diethyl ether and n-hexane $\left(\mathrm{C}_{6} \mathrm{H}_{12}\right)$ were used as diluents for method development of Ethyl 2-chloroacetate.As Ethyl 2-chloroacetate shows good response compared to ethanol, acetone, and diethyl ether than $\mathrm{C}_{6} \mathrm{H}_{12}$ Hence diluent was finalized as $\mathrm{C}_{6} \mathrm{H}_{12}$. Ethyl 2-chloroacetate is soluble in $\mathrm{n}$-hexane and insoluble in water whereas Nitrofurantoin is soluble in dimethyl formamide and insoluble in $\mathrm{C}_{6} \mathrm{H}_{12}$. Hence the determination of Ethyl 2-chloroacetate in Nitrofurantoin was finalized with $\mathrm{C}_{6} \mathrm{H}_{12}$ as diluent. The experiment was initially carried out on the DB-5(5\% phenyl-95\% dimethylpolysiloxane) column but replaced by DB-1 (100\% dimethylpolysiloxane) column for a sharp peak. The optimization was done for split ratio and injection volume up to $2 \mu \mathrm{L}$ with a split ratio of $2: 1$ of sample concentration $(200 \mathrm{mg} / \mathrm{mL})$.

\section{Method Validation}

The method validation was performed as per the ICH guidelines. The Validated method parameters include specificity, accuracy, sensitivity, precision, linearity, robustness, ruggedness and solution stability.

Table-1: Summary of method validation results for Ethyl 2-chloroacetate

\begin{tabular}{c|c|c}
\hline Validation parameter & Acceptance criteria & $\begin{array}{c}\text { The result (Ethyl 2- } \\
\text { chloroacetate) }\end{array}$ \\
\hline Specificity & The method should be specific & Specific \\
\hline \multicolumn{3}{|c|}{ Precision } \\
\hline System precision & \% RSD not more than 15.0 & 1.61 \\
\hline Repeatability & \% RSD not more than 15.0 & 1.13 \\
\hline Intermediate precision & \% RSD not more than 15.0 & 1.40 \\
\hline LOD & The peak should be detected & $0.38 \mathrm{ppm}$ \\
\hline LOQ & The peak should be quantified & $1.1 \mathrm{ppm}$ \\
\hline
\end{tabular}


RASĀYAN J. Chem.

Vol. 12 | No. 1 |355 - 359| January - March | 2019

\begin{tabular}{c|c|c}
\hline & \% RSD not more than 15.0 & 1.43 \\
\hline Linearity & Co-relation coefficient NLT 0.99 & 0.9989 \\
\hline Accuracy & Should be between $80-120 \%$ & \%8.2\% to $100.4 \%$ \\
\hline \multicolumn{3}{|c}{ Robustness } \\
\hline Flow $(0.9 \mathrm{~mL} / \mathrm{min})$ & \% RSD not more than 15.0 & 0.37 \\
\hline Flow $(1.1 \mathrm{~mL} / \mathrm{min})$ & \% RSD not more than 15.0 & 0.53 \\
\hline Column oven temperature $\left(54^{\circ} \mathrm{C}\right)$ & \% RSD not more than 15.0 & 1.16 \\
\hline Column oven temperature $\left(66^{\circ} \mathrm{C}\right)$ & \% RSD not more than 15.0 & 1.45 \\
\hline
\end{tabular}

Table-2: Linearity Results

\begin{tabular}{l|c|c}
\hline Level & Corrected Concentration $(\mathrm{ppm})$ & Area Obtained \\
\hline LOQ & 1.13 & 3.71 \\
\hline $50 \%$ & 1.18 & 6.18 \\
\hline $80 \%$ & 3.00 & 9.89 \\
\hline $100 \%$ & 3.75 & 12.99 \\
\hline $120 \%$ & 4.50 & 14.83 \\
\hline $150 \%$ & 5.63 & 18.54 \\
\hline Slope & 3.316 \\
\hline \multicolumn{2}{l|}{ Y-intercept } & 0.039 \\
\hline \multicolumn{2}{|l|}{ correlation coefficient } & 0.9989 \\
\hline
\end{tabular}

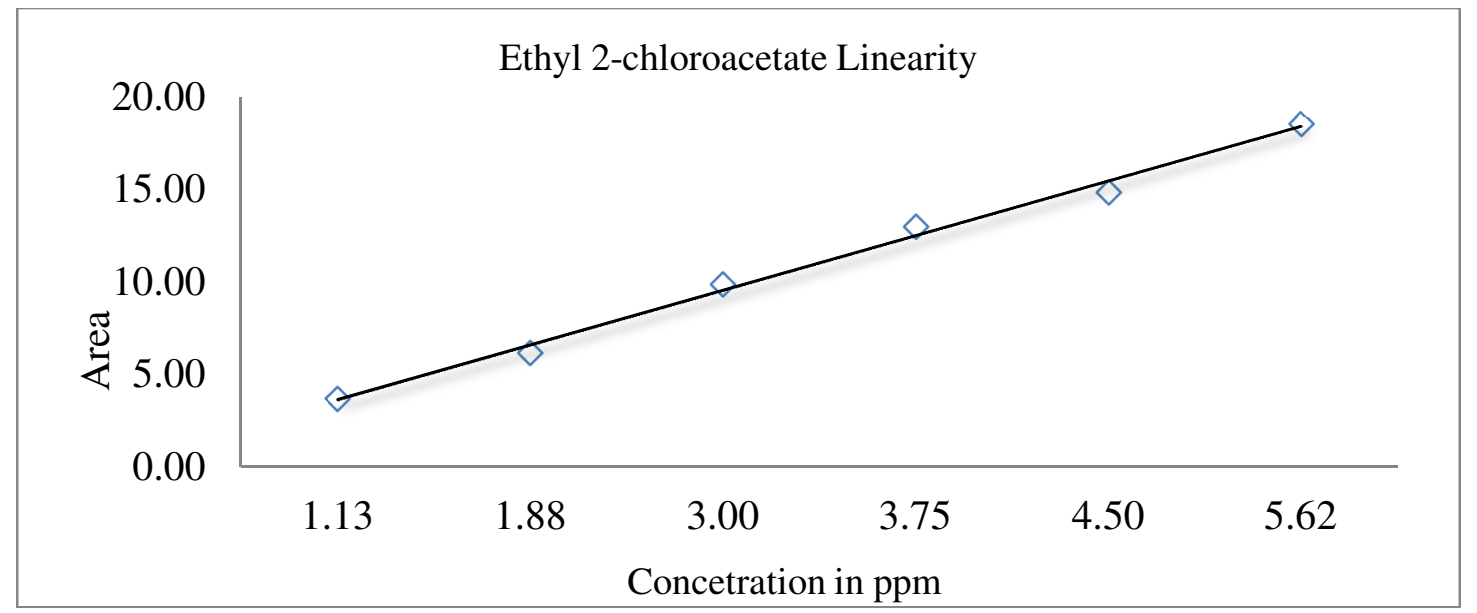

\section{Chromatograms}

Fig.-2

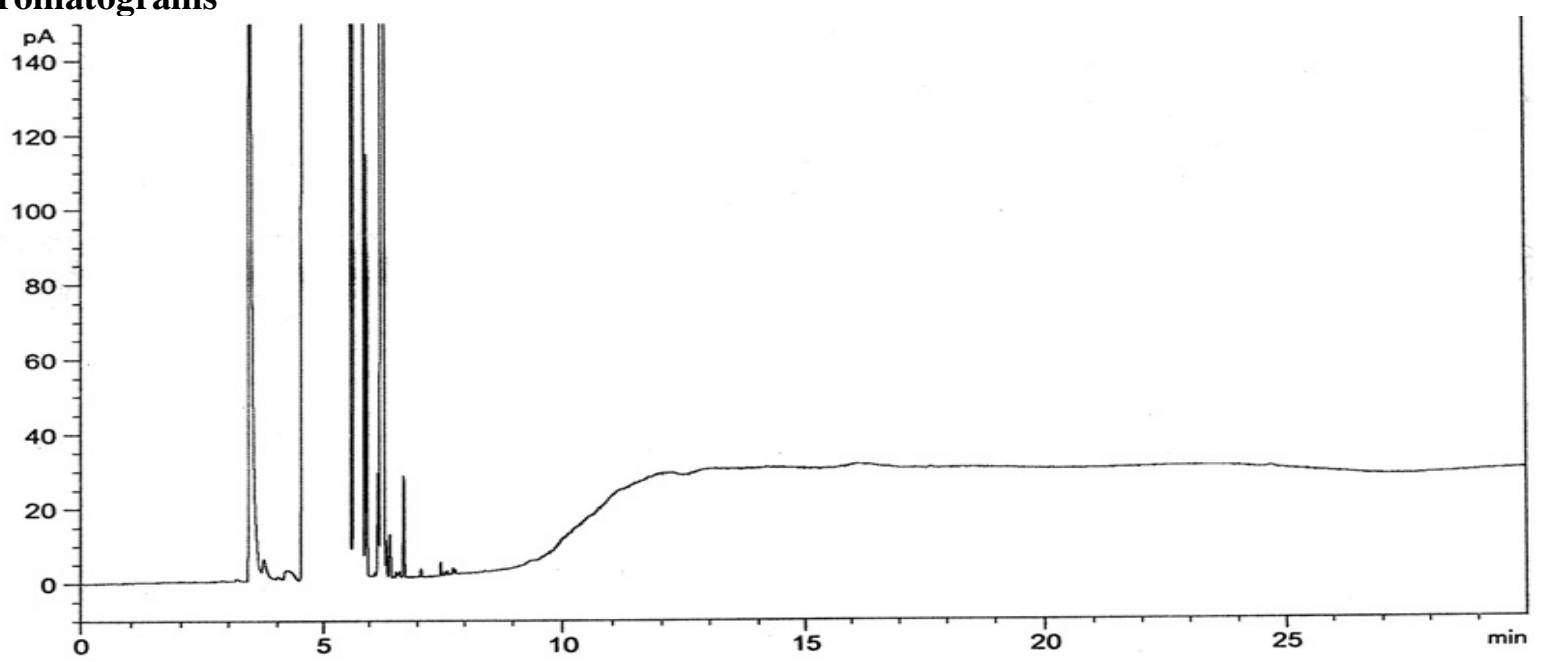

Fig-3: Blank Chromatogram 
RASĀYAN J. Chem.

Vol. 12 | No. 1 |355 - 359| January - March | 2019

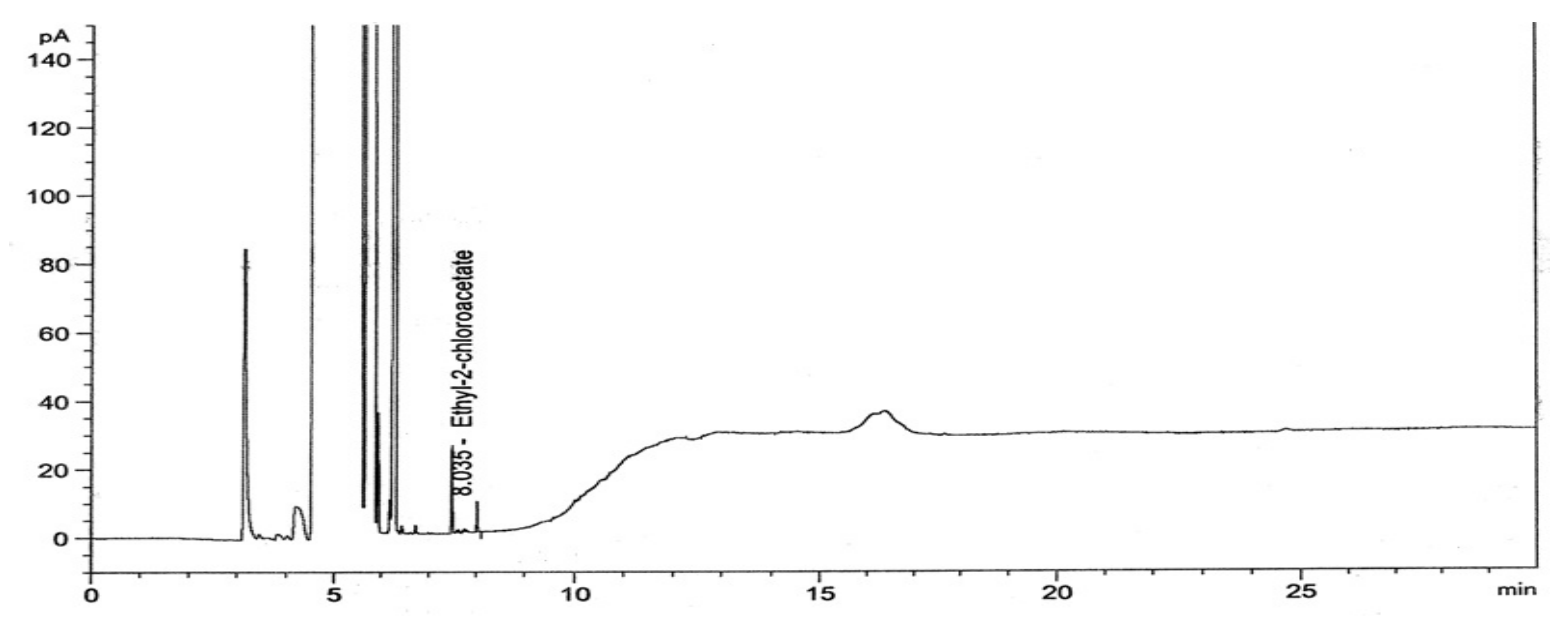

Fig.-4: Standard Chromatogram

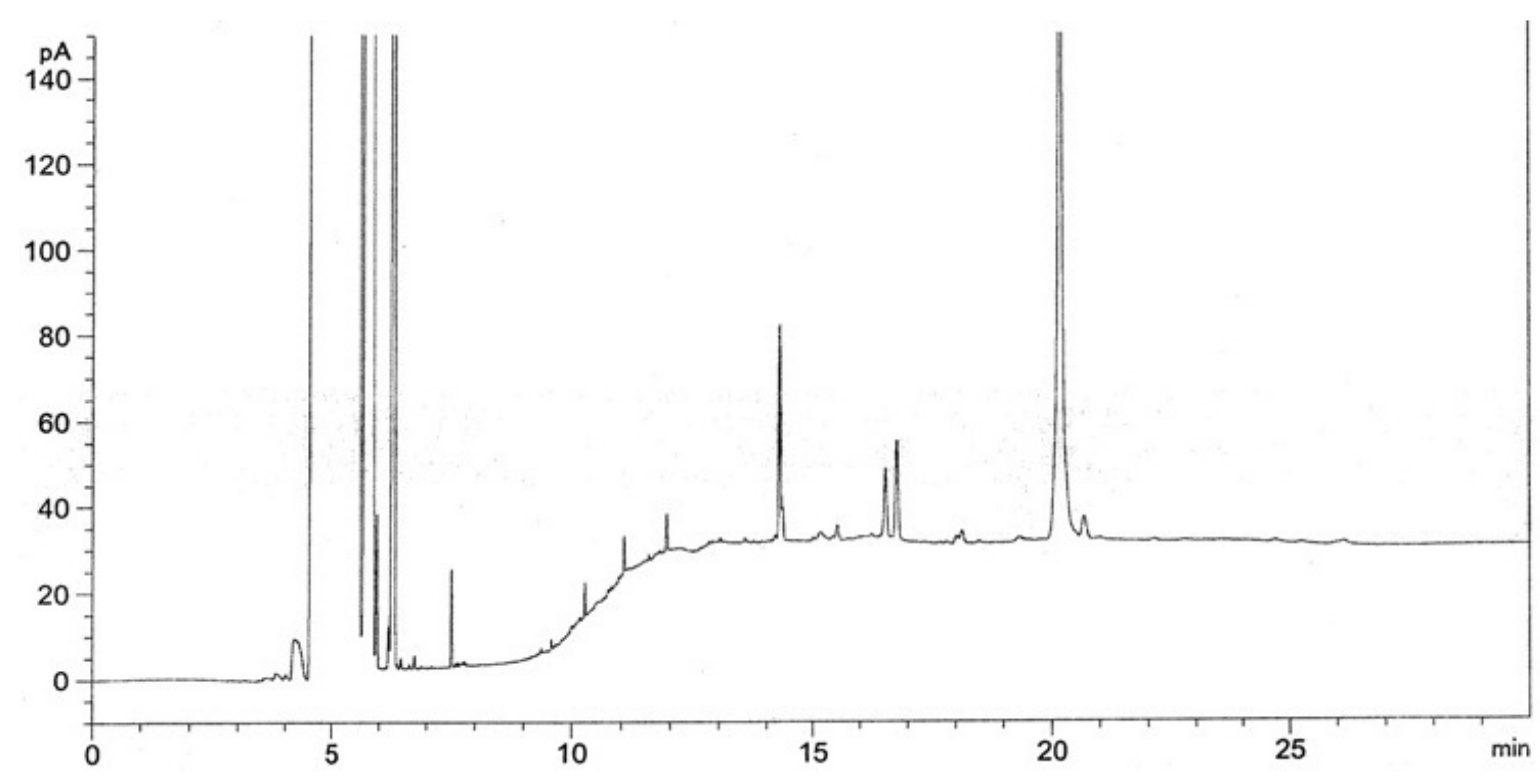

Fig.-5: Sample Chromatogram

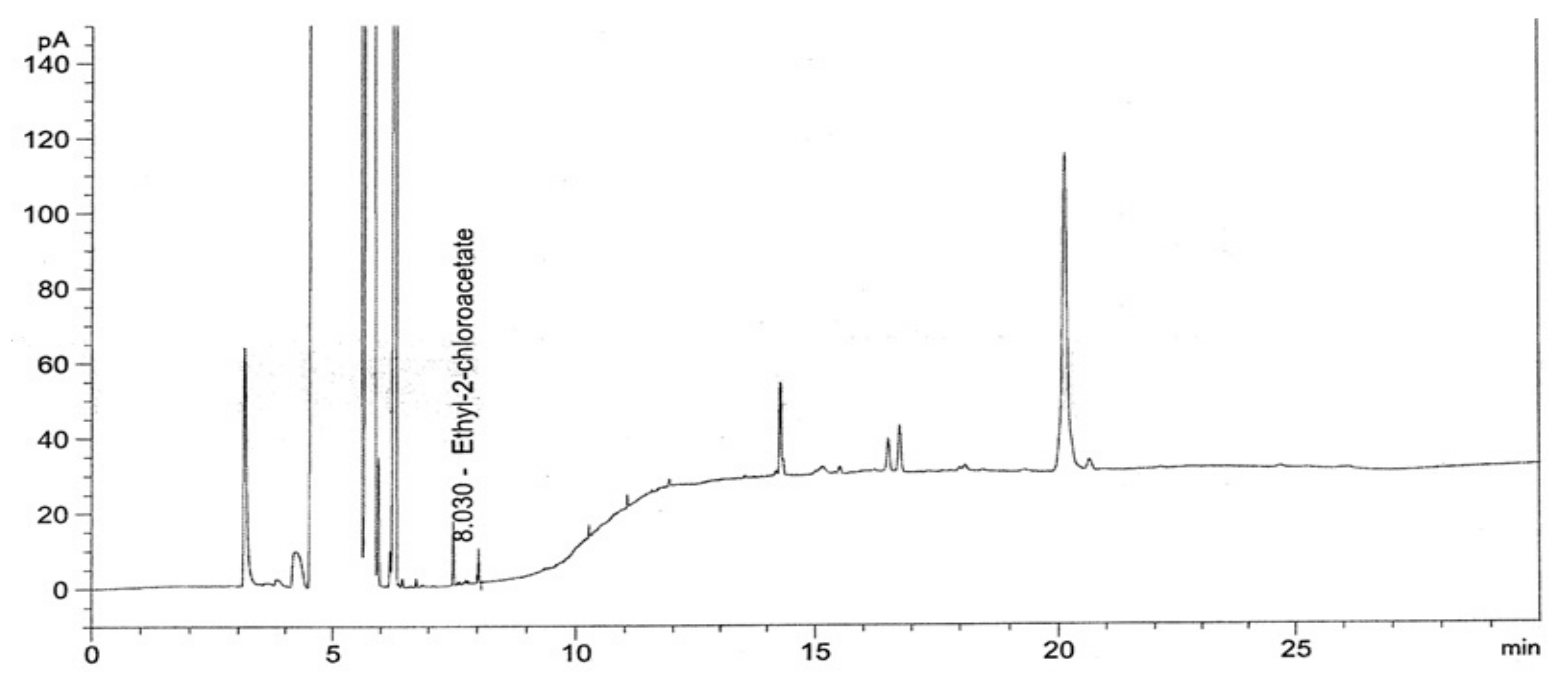

Fig.-6: Spiked Sample Chromatogram 
RASĀYAN J. Chem.

Vol. 12 | No. 1 |355 - 359| January - March | 2019

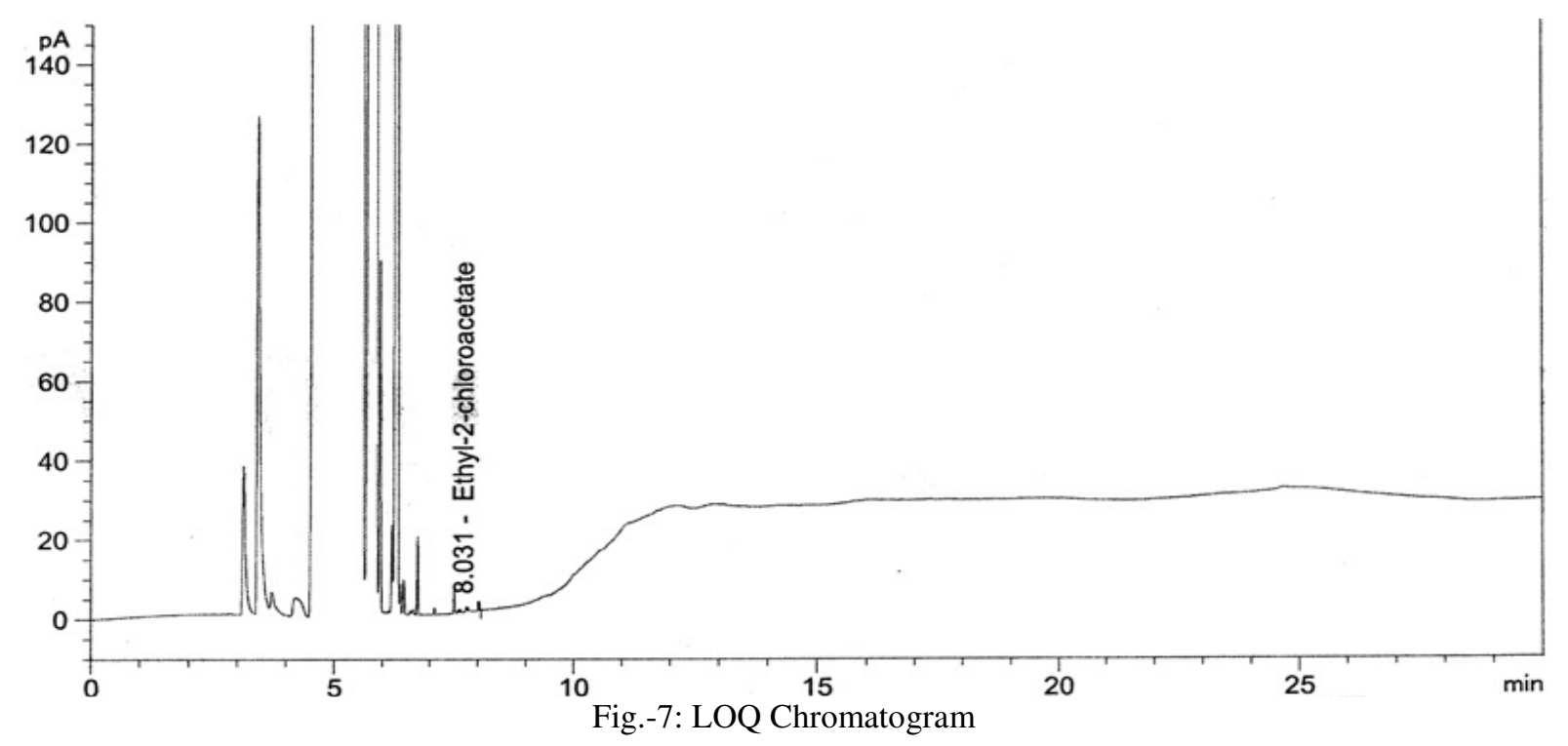

CONCLUSION

A simple and sensitive GC method has been developed and validated for the trace investigation of Ethyl 2-chloroacetate in pharmaceuticals. The validation has been conducted according to ICH guidelines. Compared with the previously reported methodologies, this method utilizes an FID detector, which is readily available in most of the testing laboratories in the pharmaceutical industry and relatively simple to use. This method is sensitive to detect $0.38 \mathrm{ppm}$ and quantify $1.1 \mathrm{ppm}$ level of Ethyl 2-chloroacetate in drug substances.

\section{REFERENCES}

1. V. Arancibia, M. Valderrama, A. Madariaga, M. C. Zuniga and R. Segura Talanta, 61,377(2003), DOI: $10.1016 / \mathrm{S} 0039-9140(03) 00276-5$

2. P. Muth, R. Metz, B. Siems, W. W. Bolten and, H. Vergin, J. Chromatogr. A 729 ,251(1996), DOI: 10.1016/0021-9673(95)00894-2

3. F. W. Kari, R. Weaver and M. C. Neville, J. Pharmacol. Exp. Ther., 280, 664(1997).

4. G. Merino, J. W. Jonker, E. Wagenaar, A. E. van Herwaarden and A. H. Schinkel, Mol. Pharmacol., 67,1758(2005), DOI: $10.1124 / \mathrm{mol} .104 .010439$

5. H. S. Rupp, R.K Munns, A.R Long, and S.M. Plakas, Journal of AOAC International, 77, 344(1994).

6. A. Guiberteau Cabanillas, M.I Acedo Valenzuela, C.A Correa, and F. Salinas, J. Chromatogr. A, 764, 243(1997), DOI: 10.1016/S0021-9673(96)00899-0

7. N. M. Angelini, O. D. Rampini and H. Mugica, Journal of AOAC International, 80, 481(1997).

8. K. K. Adkison, S. S. Vaidya, D. Y. Lee, S. H. Koo, L. Li, A. A. Mehta, A. S. Gross, J. W. Polli, Y. Lou and E. J. Lee, Br. J. Clin. Pharmacol., 66, 233(2008), DOI: 10.1111/j.1365- 2125.2008.03184.X

9. R. S. Patil, K. A. Chaitanya, P. V. D. L. S. Ravi Prakash and S. R. Patil, Current Trends in Biotechnology and Pharmacy., 6,196(2012).

10. W. A. Petri,2006, Sulfonamides, trimethoprim, sulfamethoxazole, quinolones, and agents for urinary tract infections, in Goodman \& Gilman's Pharmacological Basis of Therapeutics (Eds. L. L. Brunton, J. S. Lazo and K. L. Parker), McGraw Hill, New York, pp. 1111-1125.

11. M. Khodari, H. Mansour, H. S. El-Din and G. Mersal, Anal. Lett., 31, 251(1998), DOI: 10.1080/00032719808002043

12. E. Hammam, J. Pharm. Biomed. Anal., 30, 651(2002), DOI: 10.1016/S0731-7085 (02) 00344-8

13. P. de Lima-Neto, A.N. Correia, R.R. Portela, M.S. Juliao, G.F. Linhares-Junior, and J.E.S. de Lima, Talanta, 80(5), 1730(2010), DOI: 10.1016/j.talanta.2009.09.055

[RJC-1624/2017] 